\title{
Effects of prone position on the oxygenation of patients with acute respiratory distress syndrome
}

\author{
Intensive Care Unit, Discipline of Anesthesiology, Pain and Intensive \\ Care, Universidade Federal de São Paulo (Unifesp), São Paulo, Brazil
}

- Heloisa Baccaro Rossetti

- Flávia Ribeiro Machado

- Jorge Luiz Valiatti

- José Luiz Gomes do Amaral

\section{INTRDDUCTIロN}

The acute respiratory distress syndrome (ARDS) is characterized by non-cardiogenic pulmonary edema, associated with changes in the ventilation-perfusion ratio, intrapulmonary shunt and arterial hypoxemia.

In such circumstances, therapeutic actions are directed towards alveolar recruitment, correction of ventilation-perfusion mismatch and shunt. Physiotherapeutic maneuvers, such as mobilization, secretion drainage and sustained pulmonary insufflation aim at reopening airways in order to facilitate pulmonary ventilation. Together with such procedures, increasing the inhaled oxygen fraction tends to diminish the shunt effect and the hypoxemia. The use of positive end expiratory pressure (PEEP) and reversal of the inspiration/expiration ratio have been associated with alveolar recruitment and arterial oxygenation improvement.

However, it must be taken into account that many of these therapeutic alternatives, along with their potential benefits, entail significant and restricting adverse effects. Utilization of high levels of PEEP may be followed by hyperinsufflation of the normal lung spaces, as a result of the intrathoracic pressure, thus hindering venous return and cardiac output. This latter effect is particularly significant when an inversion of the inspiration/expiration ratio is adopted. Decreasing the time interval intended for exhalation eventually hinders complete expiration and favors dynamic hyperinsufflation. On the other hand, increasing the inhaled oxygen fraction exposes the pulmonary parenchyma to toxic concentrations of this gas.

Since 1976, a number of researchers have proven in experimental ${ }^{1-5}$ and clinical ${ }^{6-30}$ settings that the prone position (PP) produces favorable effects regarding ventilation.
Notwithstanding advances in ARDS physiopathology and clinical investigations of the effects of positioning on pulmonary gas exchanges, there is a lack of clinical experience and information regarding this matter. Such clinical investigations would enable prediction of which patients respond to this maneuver, which ones would obtain longlasting benefits and what the ideal length of time to keep the patient in the ventral recumbent position would be.

The current study had the aim of evaluating the effect of three hours of ventilation in PP, on the arterial oxygenation of patients affected by ARDS, and the safety of this maneuver.

METHODS

All patients admitted to the Intensive Care Unit with the diagnosis of ARDS during six months, from October 1997 to March 1998, were prospectively screened for the protocol. ARDS was defined as a partial pressure of oxygen $\left(\mathrm{PaO}_{2}\right)$ /fraction of inspired oxygen $\left(\mathrm{FiO}_{2}\right)$ ratio of less than 200 , with the presence of bilateral pulmonary infiltrate seen on $\mathrm{x}$-ray, and in the absence of cardiogenic pulmonary edema. Mechanical ventilation was optimized after adequate sedation and neuromuscular paralysis. PEEP was adjusted in accordance with the best static lung compliance. Patients were included in the protocol if they still needed $\mathrm{FiO}_{2}$ of more than 0.5 in order to maintain $\mathrm{PaO}_{2}$ at over $80 \mathrm{mmHg}$, after the optimization of mechanical ventilation (sedation, adjustment of PEEP according to lung compliance, mobilization and secretion drainage, and manual hyperinsufflation).

Patients with unstable fractures, intracranial hypertension, severe hemodynamic instability, laparostomy or low survival expectancy were excluded.

The protocol was approved by the Research Ethics Committee of the Institution

\section{ABSTRACT}

CONTEXT AND OBJECTIVE: Acute respiratory distress syndrome (ARDS) is characterized by arterial hypoxemia, and prone position (PP) is one possible management strategy. The objective here was to evaluate the effects of PP on oxygenation.

DESIGN AND SETTING: Non-randomized, open, prospective, controlled clinical trial, in a surgical intensive care unit at a tertiary university hospital.

METHODS: Forty-one ARDS patients underwent PP for three-hour periods. Arterial partial oxygen pressure $\left(\mathrm{PaO}_{2}\right.$ was measured immediately before changing to $P P$, after $30,60,120$ and 180 minutes in PP and 60 minutes after returning to dorsal recumbent position (DP). The paired-t and Dunnett tests were used.

RESULTS: A notable clinical improvement in oxygenation (> $15 \%$ ) was detected in $78.0 \%$ of patients. This persisted for 60 minutes after returning to DP in $56 \%$ and lasted for 12 and 48 hours in $53.6 \%$ and $46.3 \%$, respectively. Maximum improvement was seen after 30 minutes in $12.5 \%$ of responding patients and after 180 minutes in $40.6 \%$. No statistically significant associations between PP response and age, gender, weight, PEEP level, tidal volume, respiratory rate, $\mathrm{PaO}_{2} /$ $\mathrm{FiO}_{2}$ or duration of mechanical ventilation were detected. One accidental extubation and four cases of deterioration through oxygenation were detected. The 48 -hour mortality rate was $17 \%$.

CONCLUSIONS: For a significant number of ARDS patients, PP may rapidly enhance arterial oxygenation and its inclusion for management of severe ARDS is justified. However, it is not a cost-free maneuver and caution is needed in deciding on using PP.

KEY WORDS: Prone position. Acute respiratory distress syndrome. Anoxemia. Respiratory insufficiency. Artificial respiration. 
and the patients or their legal representative gave their consent.

Patients were placed in PP with the abdomen on the bed and without cushions under the shoulders or hips. Protection for the face and care regarding the catheters, tubes or probes during the maneuver were ensured. At the end of three hours, patients were put back into the supine position (SP). To evaluate the effect of ventilation in PP on oxygenation, the

$\mathrm{PaO}_{2} / \mathrm{FiO}_{2}$ values were obtained during SP, just prior to the position change, and also after 30, 60, 120 and 180 minutes in PP and 60 minutes after returning to $\mathrm{SP} . \mathrm{FiO}_{2}$ and PEEP levels were constant during the study.

Patients were considered to be responders if there was an improvement in the $\mathrm{PaO}_{2} /$ $\mathrm{FiO}_{2}$ ratio greater than $15 \%$. This laboratory parameter alone was used to define clinically important improvement in oxygenation. All

Table 1. Demographics of all patients with acute respiratory distress syndrome (ARDS) included in the study

\begin{tabular}{|c|c|c|c|c|}
\hline $\begin{array}{l}\text { Patient } \\
\text { number }\end{array}$ & Gender & $\begin{array}{c}\text { Age } \\
\text { (years) }\end{array}$ & Cause of ARDS & $\begin{array}{l}\text { Duration of } \\
\text { MV (days) }\end{array}$ \\
\hline 1 & Female & 74 & Peritonitis & 7 \\
\hline 2 & Male & 52 & Pneumonia (pancreatitis) & 2 \\
\hline 3 & Male & 78 & Pneumonia & 8 \\
\hline 4 & Male & 56 & Peritonitis & 3 \\
\hline 5 & Female & 61 & Pneumonia (acute myeloid leukemia) & 2 \\
\hline 6 & Male & 47 & Pneumonia & 4 \\
\hline 7 & Female & 35 & Puerperal endometritis & 6 \\
\hline 8 & Female & 70 & Mesenteric arterial occlusion & 7 \\
\hline 9 & Male & 37 & Pneumonia (alcoholic cirrhosis) & 1 \\
\hline 10 & Male & 41 & Mesenteric arterial occlusion & 3 \\
\hline 11 & Female & 18 & Pneumonia (systemic lupus erythematosus) & 8 \\
\hline 12 & Male & 40 & Pulmonary embolism & 4 \\
\hline 13 & Male & 22 & Pneumonia (hepatic abscess) & 1 \\
\hline 14 & Female & 31 & Peritonitis & 1 \\
\hline 15 & Male & 37 & Pancreatitis & 3 \\
\hline 16 & Male & 32 & Sepsis (hepatic failure) & 1 \\
\hline 17 & Male & 48 & Pneumocystosis & 1 \\
\hline 18 & Male & 35 & Sepsis (cardiac tamponade) & 4 \\
\hline 19 & Male & 59 & Pancreatitis & 5 \\
\hline 20 & Female & 36 & Neuroleptic malignant syndrome & 1 \\
\hline 21 & Male & 60 & Peritonitis & 8 \\
\hline 22 & Male & 63 & Pneumonia & 6 \\
\hline 23 & Female & 17 & Pneumonia & 12 \\
\hline 24 & Male & 32 & Pneumonia & 1 \\
\hline 25 & Male & 44 & Sepsis (diabetes mellitus) & 12 \\
\hline 26 & Male & 32 & Pneumonia (COPD) & 1 \\
\hline 27 & Male & 58 & Sepsis & 1 \\
\hline 28 & Male & 23 & Sepsis (cirrhosis) & 1 \\
\hline 29 & Male & 75 & Sepsis (diabetes mellitus) & 2 \\
\hline 30 & Female & 55 & Hepatic failure (cirrhosis, diabetes mellitus) & 4 \\
\hline 31 & Male & 20 & Pneumonia & 6 \\
\hline 32 & Female & 28 & Pneumonia & 4 \\
\hline 33 & Male & 32 & Sepsis (exogenous intoxication) & 4 \\
\hline 34 & Male & 83 & Sepsis (colon neoplasm) & 9 \\
\hline 35 & Male & 62 & Hepatic abscess & 2 \\
\hline 36 & Male & 40 & Multiple trauma & 2 \\
\hline 37 & Male & 71 & Pneumonia (COPD) & 4 \\
\hline 38 & Male & 32 & Peritonitis & 3 \\
\hline 39 & Male & 35 & Peritonitis & 7 \\
\hline 40 & Male & 33 & Pancreatitis & 4 \\
\hline 41 & Male & 36 & Leptospirosis & 1 \\
\hline Mean & - & 44.87 & - & 5.17 \\
\hline
\end{tabular}

$M V=$ mechanical ventilation, $C O P D=$ chronic obstructive pulmonary disease complications associated with the change in position were recorded.

Data were expressed as mean and standard deviation. The paired Student's $t$ test and the Dunnett test for multiple comparisons were used. Results were considered significant if $\mathrm{p}<0.05$.

RESULTS

A total of 41 patients were included ( 31 male and 10 female) with a mean age of 44.87 years, ranging from 17 to 83 years. Demographic data are available in Table 1.

ARDS was considered to have pulmonary origin in $43.9 \%$ of all patients. The mean $\mathrm{PaO}_{2} / \mathrm{FiO}_{2}$ ratio prior to being put in the prone position was $95.82 \pm 38.74$, ranging from 46.2 to 181.8 , with a mean PEEP level of $12.43 \pm 3.78$, ranging from 8 to $20 \mathrm{cmH}_{2} \mathrm{O}$. The mean duration of mechanical ventilation prior to the patient's inclusion in the protocol was 5.17 days, ranging from 0.5 to 9 days.

The mean values for the $\mathrm{PaO} / \mathrm{FiO}_{2}$ ratio after changing to $\mathrm{PP}$ were $125.79 \pm 56.13$, $134.90 \pm 69.24,135.60 \pm 64.93,134.50 \pm$ 58.25 and $121.60 \pm 60.00$ after $30 \mathrm{~min}, 60$ $\mathrm{min}, 120 \mathrm{~min}, 180 \mathrm{~min}$ and the return to SP, respectively (Table 2). There was a significant difference between the prior $\mathrm{PaO} / \mathrm{FiO}_{2}$ ratio and PP after $30 \mathrm{~min}(\mathrm{p}<0.0005), 60 \mathrm{~min}$ ( $\mathrm{p}$ $<0.0005), 120 \mathrm{~min}(\mathrm{p}<0.0005), 180 \mathrm{~min}$ ( $\mathrm{p}$ $<0.0005)$ and SP $(\mathrm{p}=0.003)$. These results were confirmed by the multiple comparison test (Figures 1 and 2).

A clinically important improvement in oxygenation (improvement in $\mathrm{PaO}_{2} / \mathrm{FiO}_{2}$ ratio $>15 \%$ ) was detected in 32 patients (78.0\%) (Table 2). In $65.85 \%$, such improvement took place within the first 30 minutes of PP. However, only $12.5 \%$ of the responders showed their maximum improvement within these first $30 \mathrm{~min}$ utes. For $25.0 \%, 21.8 \%$ and $40,6 \%$ of the responders, the maximum improvements were achieved after $60 \mathrm{~min}, 120 \mathrm{~min}$ and 180 min, respectively (Table 2 ).

Among the responders, 21 (65.6\%) were considered to be continuing responders, since the $\mathrm{PaO}_{2} / \mathrm{FiO}_{2}$ ratio remained at least $15 \%$ higher than the previous supine levels even after returning to SP (Table 2). Moreover, $70.0 \%$ (14 patients) of these continuing responders maintained at least this level of improvement (15\%) for 24 hours and 50.0\% (10 patients) for 48 hours after the maneuver. Four of these patients received nitric oxide due to refractory hypoxemia.

Nine patients were considered to be nonresponders. Two patients had no clinically 
significant alteration in oxygenation after PP. In seven patients (17.07), the oxygenation deteriorated in $\mathrm{PP}$, with a mean decrease in the $\mathrm{PaO}_{2} / \mathrm{FiO}_{2}$ ratio of $34.71 \%$, considering the worst value regardless of the length of time in PP. Four of them (9.75\%) did not improve again after returning to SP (Table 2).

The maneuver was relatively easy to perform, and only one patient had an accidental extubation (2.4\%). Another especially noticeable complication was facial edema with no additional morbidity. Eight deaths (19.5\%) occurred within the first 48 hours following the study procedure, but were unrelated to the maneuver. These patients had severe ARDS, with a mean $\mathrm{PaO}_{2} / \mathrm{FiO}_{2}$ ratio of $66.79 \pm 25.23$.

The duration of mechanical ventilation, age, weight, baseline $\mathrm{PaO}_{2} / \mathrm{FiO}_{2}$ ratio, tidal volume, respiratory rate and level of PEEP prior to changing the position did not seem to influence the response to this maneuver, although there was a trend towards higher weight among the responders: $74.6 \pm 14.4 \mathrm{~kg}$ and $65.0 \pm 8.8$ $\mathrm{kg}$, for the responders and non-responders, respectively ( $\mathrm{p}=0.058$; Table 3$)$.

DISCUSSIRN

The treatment of ARDS is based on oxygen therapy and ventilation under positive pressure, with high levels of positive end expiratory pressure. These procedures are restricted by the risks of oxygen toxicity and barotrauma. ${ }^{31-33}$ In this context, the prone position could enable the use of lower fractions of inhaled oxygen and lower airway pressures. Moreover, lung inflation is more homogeneous in PP, contributing towards reduction in the risks of ventilator-induced lung injury.

A series of researchers have detected optimized oxygenation after changing from SP to PP that may be clinically significant and persistent in the majority of such patients. ${ }^{6-30}$ These observations, allied to the simplicity of the procedure and its low incidence of significant adverse effects, have justified the inclusion of PP in the routine treatment for hypoxia associated with ARDS. Since 1998, we have been including the change in recumbent position from supine to prone within the strategy for severe hypoxemia treatment $\left(\mathrm{PaO}_{2} / \mathrm{FiO}_{2}<200 \mathrm{mmHg}\right.$, with optimized PEEP). Except in certain situations that constrain this maneuver (intracranial hypertension, unstable fractures, peritoneostomy and severe hemodynamic instability), ventilation in PP has been performed frequently.
Table 2. Ratio between partial arterial pressure of oxygen $\left(\mathrm{PaO}_{2}\right)$ and fraction of inspired oxygen $\left(\mathrm{FiO}_{2}\right)$ in the initial supine position and after 30, 60, 120 and 180 minutes in prone position, and in the final supine position

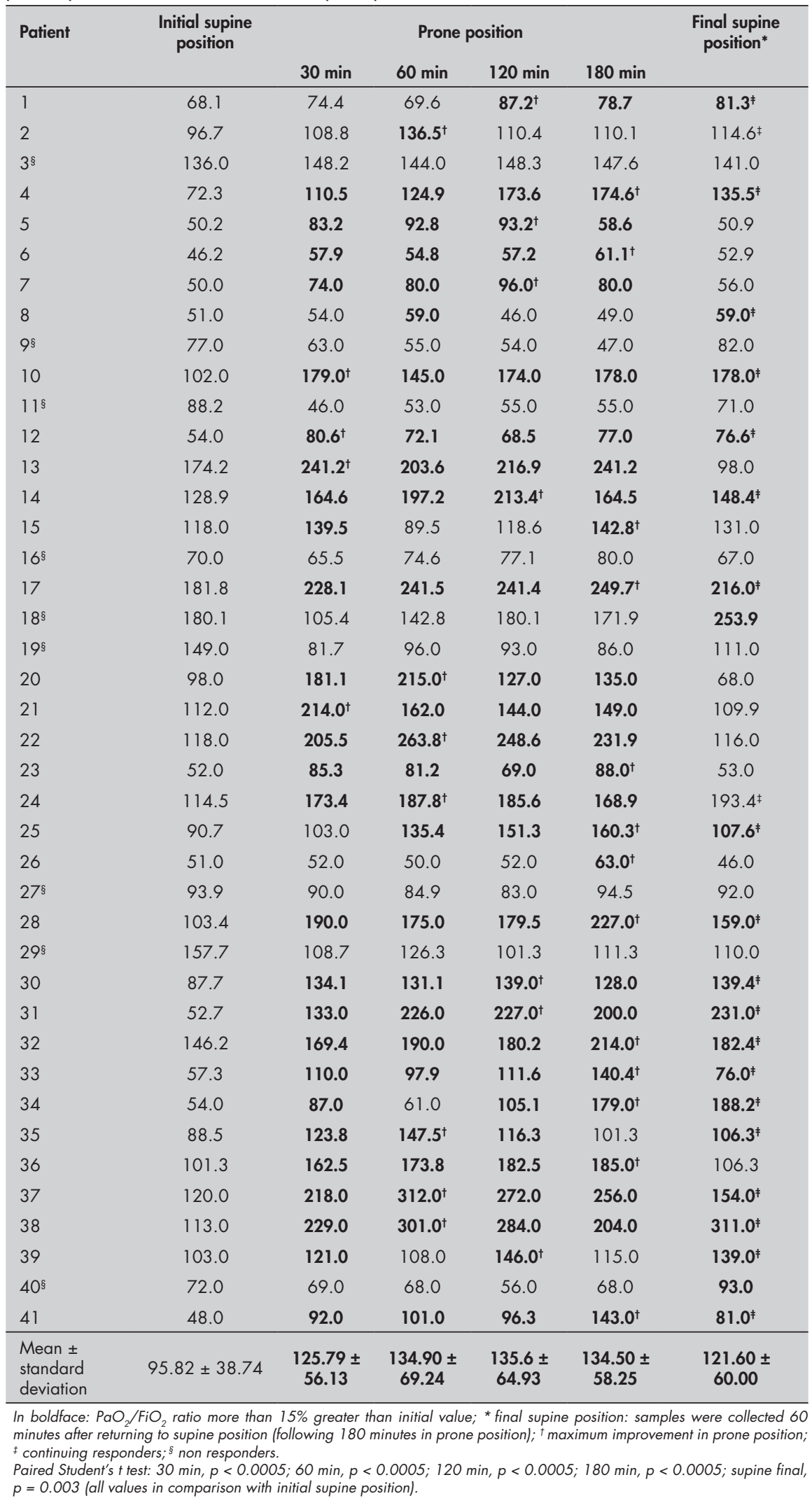




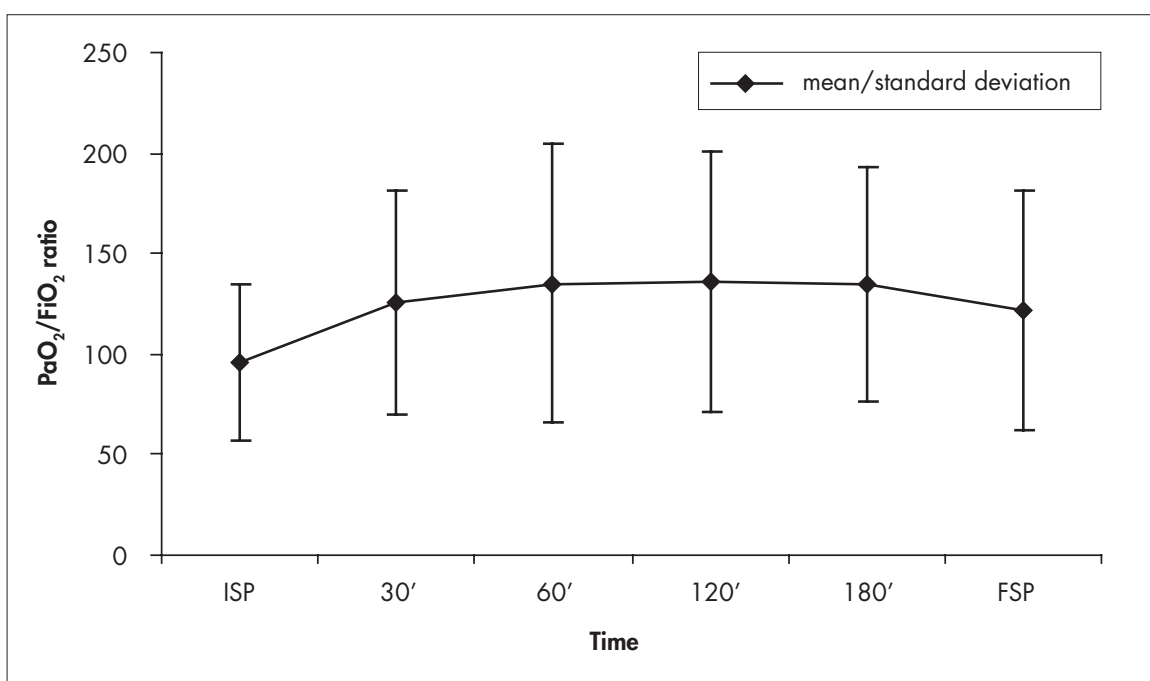

Figure 1. Ratio between partial arterial pressure of oxygen $\left(\mathrm{PaO}_{2}\right)$ and fraction of inspired oxygen $\left(\mathrm{FiO}_{2}\right)$ in the initial supine position (ISP) and final supine position (FSP) and after 30, 60, 120 and 180 minutes in prone position. Paired Student's $t$ test results: $30 \mathrm{~min}, \mathrm{p}<0.0005 ; 60 \mathrm{~min}, \mathrm{p}<0.0005 ; 120 \mathrm{~min}, \mathrm{p}<0.0005 ; 180$ $\min , p<0.0005$, final supine position, $p=0.003$ (all values refer to comparison with initial supine position).

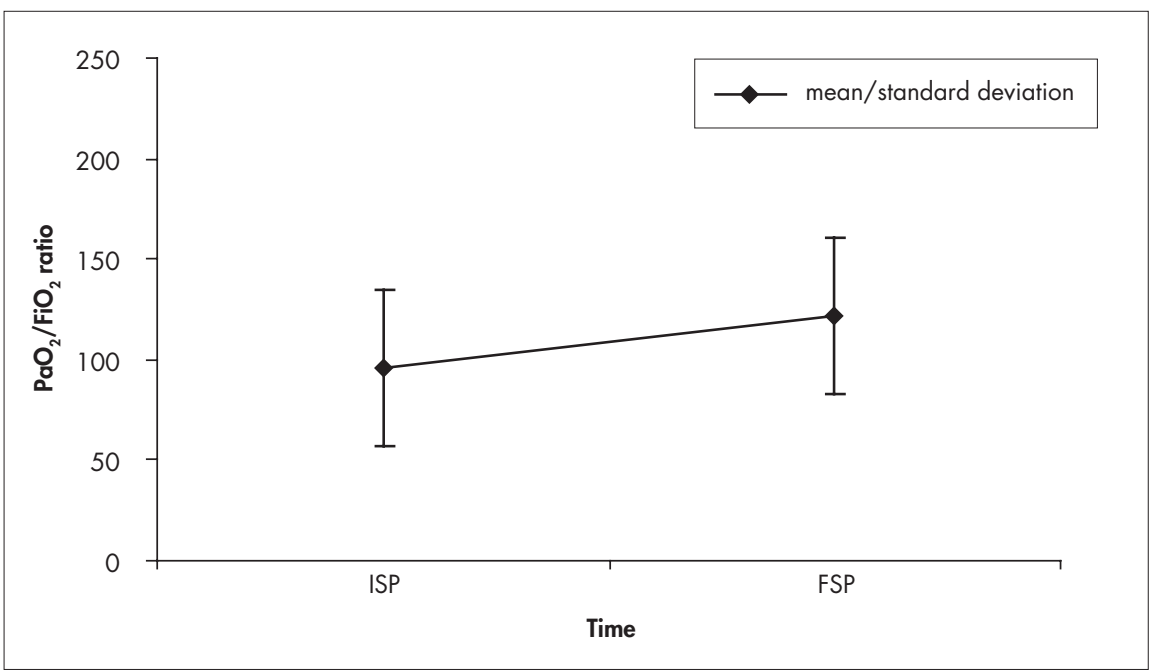

Figure 2. Ratio between partial arterial pressure of oxygen $\left(\mathrm{PaO}_{2}\right)$ and fraction of inspired oxygen $\left(\mathrm{FiO}_{2}\right)$ in the initial supine position (ISP) and final supine position (FSP) following 180 minutes in prone position. Paired Student's $t$ test result: $p=0.003$.

Table 3. Comparison between responders and non-responders to prone positioning

\begin{tabular}{lccc}
\hline Variable & Non-responders & Responders & $\mathbf{p}^{*}$ \\
\hline Age (years) & $47.9 \pm 20.6$ & $43.8 \pm 16.8$ & 0.48 \\
Weight $(\mathrm{kg})$ & $65 \pm 8.8$ & $74.6 \pm 14.4$ & 0.058 \\
$\mathrm{PaO}_{2} / \mathrm{FiO}_{2}$ ratio $^{\dagger}$ & $102.4 \pm 45.4$ & $93.4 \pm 36.6$ & 0.52 \\
$\mathrm{Tidal}$ & $490.0 \pm 119.2$ & $536.7 \pm 143.4$ & 0.34 \\
Respiratory rate & $15.3 \pm 2.8$ & $15.2 \pm 3.3$ & 0.92 \\
PEEP (mmHg) & $12.7 \pm 4.8$ & $12.3 \pm 2.9$ & 0.71 \\
Duration of $\mathrm{MV}$ (days) ${ }^{\ddagger}$ & $3.8 \pm 2.9$ & $3.8 \pm 2.8$ & 0.96 \\
\hline
\end{tabular}

$\mathrm{PaO}_{2} / \mathrm{FiO}_{2}$ ratio: ratio between partial arterial pressure of oxygen and fraction of inspired oxygen. PEEP: positive end expiratory pressure. MV: mechanical ventilation.

* Student's + test. All variables are expressed as mean \pm standard deviation; ${ }^{\dagger}$ initial supine position; ${ }^{\ddagger}$ before prone positioning.
In fact, ventilation in PP does not entail major technical difficulties. Other than the few minutes needed for changing between the types of recumbent position, adoption of the PP procedure does not substantially change the routine of medical or nursing care. Sedation is required, but it is also a requisite for the ventilation of severely hypoxemic patients.

Alternation of the recumbent position requires special attention to the placement of tubes, probes and catheters, the protection of areas at risk of injuries due to compression (eyes and other structures of the face, upper limbs and genitals), the attachment of the monitoring systems and connections of the ventilation circuit. Although these 41 patients were lying down on the bed, some authors have suggested that the abdomen should be kept free from the bed surface, by putting cushions under the shoulders and anterior iliac crests. This would facilitate expansion of the thoracic cage and diaphragm excursions. ${ }^{3}$ However, other authors have discarded such an approach, and have simply put their patients lying down on the bed. .,6,12 $^{2}$

In our study, patients were considered to be responders if there was an improvement in the $\mathrm{PaO}_{2} / \mathrm{FiO}_{2}$ ratio greater than $15 \%$. This was also considered to be a clinically significant improvement. This value was chosen on the basis of the literature, in which other authors have used changes of 10 to $20 \%$ in this ratio, or an absolute improvement of $20 \mathrm{mmHg}$ in $\mathrm{PaO}_{2}$, to define which patients were responders to PP. $6,7,17,23,27$ Using this figure of $15 \%$, most of our patients $(78.0 \%)$ did improve their oxygenation in PP as early as 30 minutes after the maneuver $(65.85 \%$ of all patients). Moreover, $62.5 \%$ had a continuing response even after changing back to SP. This has already been shown by other studies. ${ }^{6-30}$ Moreover, this has been demonstrated in different settings, such as pulmonary aspiration, ${ }^{15}$ non-ARDS patients, ${ }^{16}$ hydrostatic pulmonary edema ${ }^{17}$ and both in pulmonary and extra-pulmonary ARDS. ${ }^{18}$ Many recent reviews have also pointed out that this maneuver is associated with an improvement in oxygenation. ${ }^{34-36}$

However, one recent multicenter trial, ${ }^{37}$ with more than 300 patients randomized to be in PP for 6 hours or to remain in SP, failed to show reduced mortality in the six-hour PP group. Although it has not yet been proven that the prone position has an impact on ARDS survival, this maneuver is clearly associated with an improvement in oxygenation, as prone-positioned patients had a significant 
improvement in the $\mathrm{PaO}_{2} / \mathrm{FiO}_{2}$ ratio and in the tidal volume. It is possible that the disappointing results regarding mortality in that study were due to the short time spent in the prone position. In that paper, there was no information regarding the maximum improvement in the prone position over the course of time. This means that it is unknown how many patients were still improving their oxygenation at the end of the prone period. In our study, we have shown that, although $65 \%$ of the patients did improve within the first 30 minutes in PP, there was a continuous improvement in oxygenation, with the majority of the patients achieving the maximum $\mathrm{PaO}_{2} / \mathrm{FiO}_{2}$ ratio in the third hour after prone. This means that they were still improving at the end of the three hours, thus suggesting that a longer period of PP would be needed to achieve the maximum response. This was also suggested by a recent study in which 11 patients put in the prone position for up to 18 hours did show a continuous improvement in oxygenation. ${ }^{19}$ Unfortunately, this latter study was not a controlled trial, so it is possible that the patients improved for reasons other than PP. Nonetheless, it is possible that keeping the patients in PP for a longer time would lead to greater benefit in terms of mortality.

Another possible explanation for the absence of impact on survival lies in the fact that it might be difficult to show such an impact since hypoxemia is not a major cause of death among ARDS patients. Most of these patients die from multiple organ dysfunction syndrome and the main benefit of this maneuver is to allow better oxygenation. In another trial, ${ }^{37}$ patients were put in the prone position except if the $\mathrm{PaO}_{2} / \mathrm{FiO}_{2}$ ratio was greater than 200 with a PEEP level of 5 . This meant that, even if less critically ill patients were included, which may have contributed to the absence of any effect on survival, the effect on oxygenation could still be demonstrated. This had already been shown in another study in which patients with acute lung injury (ALI) showed an improvement in oxygenation. ${ }^{16}$ If only very critically ill patients had been included in the Gatinonni trial, ${ }^{37}$ the results relating to mortality might have been different, since this maneuver undoubtedly increases oxygenation, and this may have been more important among critically hypoxemic patients. This was suggested because, in the subgroup of patients with the lowest $\mathrm{PaO}_{2} / \mathrm{FiO}_{2}$ ratio, there was a significant reduction in mortality.

This concept is important, as it is not a cost-free maneuver. Although in the literature the prone position has not been associated with major adverse events, we found a small percentage of patients that had a clinically important and persistent deterioration of saturation. In three instances (cases 9, 18 and 40), returning the patients to the dorsal recumbent position reversed this hazard, thus suggesting that PP was responsible for the deterioration in oxygenation. Worsening of oxygenation after putting the patient into $\mathrm{PP}$ is not a frequent finding in the literature. In one study, a patient died soon after being placed in SP because of oxygenation deterioration in $\mathrm{PP}$, and this was considered to be an adverse event related to the maneuver. ${ }^{16}$ It is possible that this situation has been underestimated in other trials and therefore its importance is now underscored.

Another concern is the episode of accidental extubation in our sample. This is a troublesome situation, since our intensive care unit (ICU) team is well trained and very used to the maneuver. Even in this setting, accidents may happen and, because of the severity of these patients, extubation might be responsible for an irreversible deterioration. Our patients, although relatively young, were critically ill, as shown by the low $\mathrm{PaO}_{2} / \mathrm{FiO}_{2}$ ratio, high PEEP levels and the high acute mortality rate (19\% within 48 hours). Since most of them presented hypoxemia or needed high $\mathrm{FiO}_{2}$ levels, it seemed reasonable to put them in PP, regardless of the potential danger that it could cause. As there is no proven benefit in terms of mortality, patients that are not critically ill should not be routinely put in PP.

Unfortunately, we could not find a recognizable characteristic or marker to determine whether or not a patient would be a responder or, even more importantly, would deteriorate in PP. Until we can identify which patients should be put into the prone position, it is important to promptly recognize this subgroup of nonresponding patients, so that the maneuver can be interrupted immediately. This is reinforced by the fact that this maneuver, at least from the evidence available, has no impact on mortality. The cost-benefit ratio in this subgroup of patients is fairly discouraging.

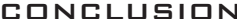

The analysis of the results achieved in this study leads us to conclude that, in a considerable number of patients with ARDS, the change from the SP to the PP is responsible for a sustained improvement in arterial oxygenation. In some patients, however, worsening follows the change in position and so far it has not been possible to identify such patients. Since there is no proven impact on mortality, ventilation in $\mathrm{PP}$ is potentially beneficial and deserves to be taken into account for the treatment of severe hypoxemia associated with ARDS. For other cases, it needs to be used with caution.
1. Albert RK, Leasa D, Sanderson M, Robertson HT, Hlastala MP. The prone position improves arterial oxygenation and reduces shunt in oleic-acid-induced acute lung injury. Am Rev Respir Dis. 1987;135(3):628-33.

2. Broccard AF, Shapiro RS, Schmitz LL, Ravenscraft SA, Marini JJ. Influence of prone position on the extent and distribution of lung injury in a high tidal volume oleic acid model of acute respiratory distress syndrome. Crit Care Med. 1997;25(1):16-27.

3. Moreno F, Lyons HA. Effect of body posture on lung volumes. J Appl Physiol. 1961;16:27-9,

4. Lamm WJ, Graham MM, Albert RK. Mechanism by which the prone position improves oxygenation in acute lung injury. Am J Respir Crit Care Med. 1994;150(1):184-93.

5. Beck KC, Vettermann J, Rehder K. Gas exchange in dogs in the prone and supine positions. J Appl Physiol. 1992;72(6):2292-7.

6. Blanch L, Mancebo J, Perez M, et al. Short-term effects of prone position in critically ill patients with acute respiratory distress syndrome. Intensive Care Med. 1997;23(10):1033-9.
7. Chatte G, Sab JM, Dubois M, Sirodot M, Gaussorgues P, Robert D. Prone position in mechanically ventilated patients with severe acute respiratory failure. Am J Respir Crit Care Med. 1997;155(2):473-8

8. Douglas WW, Rehder K, Beynen FM, Sessler AD, Marsh HM. Improved oxygenation in patients with acute respiratory failure: the prone position. Am Rev Respir Dis. 1977;115(4):559-66.

9. Gattinoni L, Pelosi P, Crotti S, Valenza F. Effects of positive end-expiratory pressure on regional distribution of tidal volume and recruitment in adult respiratory distress syndrome. Am J Respir Crit Care Med. 1995;151(6):1807-14.

10. Stocker R, Neff T, Stein S, Ecknauer E, Trentz O, Russi E. Prone postioning and low-volume pressure-limited ventilation improve survival in patients with severe ARDS. Chest. 1997;111(4):1008-17.

11. Pappret D, Rossaint R, Slama K, Gruning T, Falke KJ. Influence of positioning on ventilation-perfusion relationships in severe adult respiratory distress syndrome. Chest. 1994;106(5):1511-6.
12. Pelosi P, Croci M, Calappi E, et al. The prone positioning during general anesthesia minimally affects respiratory mechanics while improving functional residual capacity and increasing oxygen tension. Anesth Analg. 1995;80(5):955-60.

13. Reed JH Jr, Wood EH. Effect of body position on vertical distribution of pulmonary blood flow. J Appl Physiol. 1970;28(3):303-11.

14. Sinclair SE, Albert RK. Altering ventilation-perfusion relationships in ventilated patients with acute lung injury. Intensive Care Med. 1997;23(9):942-50.

15. Easby J, Abraham BK, Bonner SM, Graham S. Prone ventilation following witnessed pulmonary aspiration: the effect on oxygenation. Intensive Care Med. 2003;29(12):2303-6.

16. Venet $\mathrm{C}$, Guyomarc'h S, Migeot $\mathrm{C}$, et al. The oxygenation variations related to prone positioning during mechanical ventilation: a clinical comparison between ARDS and non-ARDS hypoxemic patients. Intensive Care Med. 2001;27(8):1352-9. 
17. Nakos G, Tsangaris I, Kostanti E, et al. Effect of the prone position on patients with hydrostatic pulmonary edema compared with patients with acute respiratory distress syndrome and pulmonary fibrosis. Am J Respir Crit Care Med. 2000;161(2 Pt 1):360-8

18. Lim CM, Kim EK, Lee JS, et al. Comparison of the response to the prone position between pulmonary and extrapulmonary acute respiratory distress syndrome. Intensive Care Med. 2001;27(3):477-85.

19. McAuley DF, Giles S, Fichter H, Perkins GD, Gao F. What is the optimal duration of ventilation in the prone position in acute lung injury and acute respiratory distress syndrome? Intensive Care Med. 2002;28(4):414-8.

20. Fridrich P, Krafft P, Hochleuthner H, Mauritz W. The effects of long-term prone positioning in patients with traumainduced adult respiratory distress syndrome. Anesth Analg. 1996;83(6):1206-11.

21. Servillo G, Roupie E, De Robertis E, et al. Effects of ventilation in ventral decubitus position on respiratory mechanics in adult respiratory distress syndrome. Intensive Care Med. 1997;23(12):1219-24

22. Mure M, Martling C, Lindahl SG. Dramatic effect on oxygenation in patients with severe acute lung insufficiency treated in the prone position. Crit Care Med. 1997;25(9):1539-44.

23. Flaatten $\mathrm{H}$, Aardal S, Hevroy O. Improved oxygenation using the prone position in patients with ARDS. Acta Anaesthesiol Scand. 1998;42(3):329-34

24. Pelosi P, Tubiolo D, Mascheroni D, et al. Effects of the prone position of respiratory mechanics and gas exchange during acute lung injury. Am J Respir Crit Care Med. 1998;157(2):387-93.
25. Guerin C, Badet M, Rosselli S, et al. Effects of prone position on alveolar recruitment and oxygenation in acute lung injury. Intensive Care Med. 1999;25(11):1222-30.

26. Germann P, Poschl G, Leitner C, et al. Additive effect of nitric oxide inhalation on the oxygenation benefit of the prone position in the adult respiratory distress syndrome. Anesthesiology. 1998;89(6):1401-6.

27. Papazian L, Bregeon F, Gaillat F, et al. Respective and combined effects of prone position and inhaled nitric oxide in patients with acute respiratory distress syndrome. Am J Respir Crit Care Med. $1998 ; 157(2): 580-5$

28. Martinez M, Diaz E, Joseph D, et al. Improvement in oxygenation by prone position and nitric oxide in patients with acute respiratory distress syndrome. Intensive Care Med. 1999;25(1):29-36.

29. Jolliet P, Bulpa P, Ritz M, Ricou B, Lopez J, Chevrolet JC. Additive beneficial effects of the prone position, nitric oxide, and almitrine bismesylate on gas exchange and oxygen transport in acute respiratory distress syndrome. Crit Care Med. 1997;25(5):786-94.

30. Vollman KM, Bander JJ. Improved oxygenation utilizing a prone positioner in patients with acute respiratory distress syndrome. Intensive Care Med. 1996;22(10):1105-11.

31. Dreyfuss D, Soler P, Saumon G. Mechanical ventilation-induced pulmonary edema. Interaction with previous lung alterations. Am J Respir Crit Care Med. 1995;151(5):1568-75.

32. Froese AB, Bryan AC. Effects of anesthesia and paralysis on diaphragmatic mechanics in man. Anesthesiology. 1974;41(3):242-55.

33. Gattinoni L, Mascheroni D, Torresin A, et al. Morphological response to positive end expiratory pressure in acute respiratory failure. Computerized tomography study. Intensive Care Med. 1986;12(3):137-42
34. Rialp G, Mancebo J. Prone positioning in patients with acute respiratory distress syndrome. Respir Care Clin N Am. 2002;8(2):237-45, vi-vii.

35. Pelosi P, Brazzi L, Gattinoni L. Prone position in acute respiratory distress syndrome. Eur Respir J. 2002;20(4):1017-28.

36. Ward NS. Effects of prone position ventilation in ARDS. An evidence-based review of the literature. Crit Care Clin. 2002;18(1):35-44

37. Gattinoni L, Tognoni G, Pesenti A, et al. Effect of prone positioning on the survival of patients with acute respiratory failure. N Engl J Med. 2001;345(8):568-73.

Sources of funding: Non Conflict of interest: None Date of first submission: September 13, 2004

Last received: January 11, 2006

Accepted: January 12, 2006

\section{AUTHDR INFDRMATIDN}

Heloisa Baccaro Rossetti, MSc. Chief physiotherapist, Intensive Care Unit, Discipline of Anesthesiology, Pain and Intensive Care, Universidade Federal de São Paulo (Unifesp), São Paulo, Brazil.

Flávia Ribeiro Machado, MD, PhD. Professor, Intensive Care Unit, Discipline of Anesthesiology, Pain and Intensive Care, Universidade Federal de São Paulo (Unifesp), São Paulo, Brazil

Jorge Luiz Valiatti, MD, PhD. Intensive Care Unit, Discipline of Anesthesiology, Pain and Intensive Care, Universidade Federal de São Paulo (Unifesp), São Paulo, Brazil.

José Luiz Gomes do Amaral, MD, PhD. Full professor, Intensive Care Unit, Discipline of Anesthesiology, Pain and Intensive Care, Universidade Federal de São Paulo (Unifesp), São Paulo, Brazil.

\section{Address for correspondence:}

José Luiz Gomes do Amaral

Disciplina de Anestesiologia, Dor e Terapia Intensiva - Universidade Federal de São Paulo (Unifesp)

Rua Botucatu, 740 - Vila Clementino

São Paulo/SP - Brasil - CEP 04024-900

Tel. (+55 11) 5576-4069

E-mail: jlgamaral@uol.com.br
RESUMロ

Efeitos da posição em pronação na oxigenação de pacientes com síndrome do desconforto respiratório agudo

CONTEXTO E OBJETIVO: A síndrome de desconforto respiratório agudo (SDRA) é caracterizada por hipoxemia arterial e a posição em pronação (PP) é uma das estratégias de tratamento. O objetivo do trabalho é avaliar os efeitos da PP na oxigenação.

TIPO DE ESTUDO E LOCAL: Estudo clínico não randomizado, aberto, prospectivo, controlado, realizado em uma unidade de terapia intensiva cirúrgica de hospital universitário terciário.

MÉTODOS: 41 pacientes com SDRA com idade variando entre 17 e 83 anos foram submetidos a PP du rante três horas. Determinou-se a pressão parcial de oxigênio arterial imediatamente antes da mudança para PP, após 30, 60, 120 e 180 minutos em PP e 60 minutos depois de retornar para a posição dorsal (PD). Os resultados foram analisados através dos testes T pareado e Dunnett, e considerados significantes se $\mathrm{p} \leq 0.05$.

RESULTADOS: Melhora clínica significativa na oxigenação (> 15\%) foi detectada em $78 \%$ dos pacientes. Após 60 minutos do retorno para a posição dorsal, o efeito persistiu em 56\% dos pacientes e, após 12 e 48 horas, em $53.6 \%$ e $46.3 \%$, respectivamente. A melhora máxima ocorreu após 30 minutos apenas em $12.5 \%$ dos respondedores e em $40,6 \%$ após 180 minutos. Não foi demonstrada associação significativa entre a resposta à PP e idade, gênero, peso, nível de pressão expiratória final positiva, volume corrente, freqüência respiratória, relação $\mathrm{PaO} 2 / \mathrm{FiO} 2$ ou duração da ventilação mecânica. Somente uma desintubação acidental e sete casos de deterioração da oxigenação foram detectados. A mortalidade em 48 horas foi de $17 \%$

CONCLUSÕES: Em um número significativo de pacientes com SDRA, a PP pode rapidamente melhorar a oxigenação arterial e sua inclusão no tratamento da SDRA grave está justificada. Entretanto, não se trata de uma manobra inócua e cautela é necessária quando da decisão de colocar um paciente em pronação.

PALAVRAS-CHAVE: Decúbito dorsal. Síndrome do desconforto respiratório agudo. Hipoxemia. Insuficiência respiratória. Respiração artificial. 